\title{
Review
}

\section{Application of Antioxidants in Food Processing Industry: Options to Improve the Extraction Yields and Market Value of Natural Products}

\author{
Muluken Kebede, MSc'; Shimelis Admassu, PhD $^{2 *}$ \\ 'Department of Chemical Engineering, Institute of Technology, University of Hawassa, Hawassa, Ethiopia \\ ${ }^{2}$ Department of Food Engineering, School of Chemical and Bioenginering, Addis Ababa Uinversity, Addis Ababa, Ethiopia
}

\section{${ }^{*}$ Corresponding author}

Shimelis Admassu, PhD

Associate Professor, Department of Food Engineering, School of Chemical and Bioenginering,Addis Ababa Uinversity, P.O.Box 3338I.Addis Ababa, Ethiopia; E-mail: shimelisemire@yahoo.com

\section{Article information}

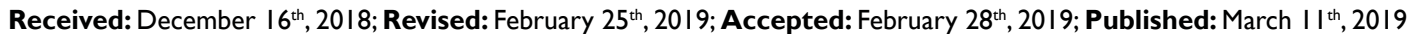

\section{Cite this article}

Kebede M,Admassu S. Application of antioxidants in food processing industry: Options to improve the extraction yields and market value of natural products. Adv Food Technol Nutr Sci Open J. 2019; 5(2): 38-49. doi: I0.17|40/AFTNSOJ-5-155

\section{ABSTRACT}

Antioxidants are substances that are capable of slowing down the autoxidation process of other compounds or neutralize free radicals. They have been used in food processing industries as a means to hinder oxidation, enhance flavor, aroma and color. Antioxidants have also been used and valued for treatment of various diseases such as cancer and coronary heart disease. Even though, synthetic antioxidants including butylated hydroxytoluene (BHT) may cause side effects to human health and presumed unsafe to be used, they are the ones in a great use in the area of food processing industries as most food and pharmaceutical products contain them. The objective of this review work is therefore to provide an overview of the findings related to the presence of antioxidants in plant sources particularly those that have not been extensively studied and evaluated such as fruits and vegetables by-products. To minimize their effects, researches have been conducted aiming to substitute them with antioxidants from natural sources. Recent studies show that synthesis of natural antioxidants from fruit and vegetable waste has gained great attention. Further research has to be performed on plant phenols and processing of agricultural and industrial by-products as a potential source for extraction of antioxidants. In order to increase the affirmative effect and usefulness of antioxidants to human health, it is recommended to follow a balanced and varieties of diets instead of taking antioxidant supplements on a regular basis. Therefore, we should consume a diet high in antioxidant rich fruits and vegetables day by day. Furthermore, nutritional importance, promotion of health and prevention against damages caused by free radicals can lead to the potential applications of antioxidants in food industries in more intensified approaches. In a nutshell, antioxidant foods and ingredients are an important component of the food industry and thus reconsidering the health implications of adding antioxidants to foods require unfathomable investigations.

\section{Keywords}

Antioxidants; Free radical; Food processing; Plant phenols; By-products; phytochemicals.

\section{Abbreviations}

BHT: Butylated hydroxytoluene; BHA: Butylated hydroxyanisole; PG: Propyl gallate; DG: Dodecyl gallate; ROS: Reactive Oxygen Species; RNS: Reactive Nitrogen Species.
\end{abstract}

\section{INTRODUCTION}

A ntioxidant is a molecule stable enough to donate an electron Ato a rampaging free radical and neutralize it, thus reducing its capacity to damage. These antioxidants delay or inhibit cellular damage mainly through their free radical scavenging property. ${ }^{1}$ These low-molecular-weight antioxidants can safely interact with free radicals and terminate the chain reaction before vital molecules are damaged. Some of such antioxidants, including glutathione, ubiquinol, and uric acid, are produced during normal metabolism in the body. ${ }^{2}$ Other lighter antioxidants are found in the diet. Although there are several enzymes system within the body that scavenges free radicals, the principle micronutrient (vitamins) antioxidants are vitamin $\mathrm{E}$ ( $\alpha$-tocopherol), vitamin $\mathrm{C}$ (ascorbic acid),

(0) Copyright 2019 by Admassu S. This is an open-access article distributed under Creative Commons Attribution 4.0 International License (CC BY 4.0), which allows to copy, redistribute, remix, transform, and reproduce in any medium or format, even commercially, provided the original work is properly cited. 
and $\mathrm{B}$-carotene. ${ }^{3}$ The body cannot manufacture these micronutrients, so they must be supplied in the diet.

In the $20^{\text {th }}$ century, antioxidants entered in the widely emerging food industry as an important means to limit the degradation of stored foods as a result of oxidation process. ${ }^{2}$ Antioxidants are substances that may protect cells from the damage caused by unstable molecules known as free radicals. Free radicals are any chemical species capable of independent existence with one or more unpaired electrons in their outermost shell, which seek out and capture electrons from other substances to achieve neutrality. ${ }^{3,4}$ An antioxidant is a molecule capable of slowing or preventing the oxidation of other molecules or neutralize free radicals. ${ }^{5}$

Oxidation is a chemical reaction that transfers electrons from a substance to an oxidizing agent. Oxidation reactions can be damaging to cells since they can produce free radicals which initiate chain reactions, leading to membrane and other lipid per oxidation, DNA damage, etc, ${ }^{6}$ Antioxidants ends these chain reactions by removing free radical intermediates and inhibit other oxidation reactions by being oxidized themselves. As a result, antioxidants are often reducing agents such as thiols, ascorbic acid or polyphenols.? Although oxidation reactions are crucial for life, they can also be damaging; hence, plants and animals maintain complex systems of multiple types of antioxidants, such as glutathione, vitamin $\mathrm{C}$, vitamin E, $\alpha$-carotene, selenium and polyphenol as well as enzymes such as catalase, superoxide dismutase and various peroxidases. ${ }^{1,8}$ Antioxidants are abundant in fruits and vegetables, as well as in other foods including nuts, grains, coffee, tea, wine, herbs, spices and some meats, poultry and fish. ${ }^{9,10}$

In the recent years, considerable research has been carried out evaluating natural substances as antioxidative additives in food products, leading to novel combinations of antioxidants and the development of novel food products. In addition to their antioxidative capacity, these natural additives have positive effects on the human body with documented health benefits.

\section{CLSSSIFICAION OF ANTIOXIDANTS}

In nature, various antioxidants are commonly found in food products. Literature suggests the availability of a wide range of antioxidants and their classifications based on where they perform their activities, their mode of action (preventive and scavenging), their background and their biochemical characteristics. ${ }^{11}$ Natural antioxidants, synthetic antioxidants, dietary antioxidant and endogenous antioxidant are identified as the most common antioxidants and play an important role in preservation of food. ${ }^{8}$ Antioxidant also can be mostly classified into enzymatic (Superoxide dismutase, catalase, glutathione systems) and non-enzymatic (ascorbic acid, glutathione, melatonin, tocopherols and tocotrienols (vitamin E), uric acid).

\section{Dietary Antioxidants}

Dietary antioxidants include ascorbate, tocopherols, carotenoids and bioactive plant phenols. The health benefits of fruits and vegetables are largely due to the antioxidant vitamins supported by the large number of phytochemicals, some with greater antioxidant properties. ${ }^{12-14}$ Vitamin $\mathrm{C}$, vitamin E, B-carotene and other carotenoids and oxycarotenoids, e.g., lycopene and lutein are among the most widely studied dietary antioxidants. ${ }^{8}$

In extracellular fluids vitamin $C$ is considered as the most important water-soluble antioxidant. It is capable of neutralizing reactive oxygen species (ROS) in the aqueous phase before lipid per oxidation is initiated. Vitamin E, a major lipid soluble antioxidant, is the most effective chain-breaking antioxidant within the cell membrane where it protects membrane fatty acids from lipid per oxidation. It has been cited that vitamin $C$ is capable of regenerating vitamin $\mathrm{E} .{ }^{15}$

B-carotene and other carotenoids are also believed to provide antioxidant protection to lipid-rich tissues. Research suggests that $\beta$-carotene may work synergistically with other vitamins. ${ }^{16}$ In plants, flavonoids serve as protectors against a wide variety of environmental stresses while, in humans, flavonoids appear to function as "biological response modifiers". Flavonoids have been demonstrated to have anti-inflammatory, antiallergenic, anti-viral, anti-aging, and anti-carcinogenic activity. ${ }^{8}$

\section{Endogenous Antioxidants}

In addition to dietary antioxidants, the body relies on several endogenous defense mechanisms to help protect against free radical-induced cell damage. The antioxidant enzymes-glutathione peroxidase, catalase, and superoxide dismutase (SOD)-metabolize oxidative toxic intermediates and require micronutrient cofactors such as selenium, iron, copper, zinc, and manganese for optimum catalytic activity. It has been suggested that an inadequate dietary in take of these trace minerals may compromise the effectiveness of these antioxidant defense mechanisms. ${ }^{16}$ Glutathione, an important water-soluble antioxidant, is synthesized from the aminoacids glycine, glutamate, and cysteine. Glutathione directly quenches ROS such as lipid peroxides, and also plays a major role in xenobiotic metabolism. ${ }^{17}$

Lipoic acid, yet another important endogenous antioxidant, categorized as a "thiol" or "biothiol," is a sulfur-containing molecule that is known for its involvement in the reaction that catalyzes the oxidative decarboxylation of alpha-keto acids, such as pyruvate and alpha ketoglutarate, in the Krebs cycle. ${ }^{8}$

\section{Exogenous Antioxidants}

Exogenous antioxidants can derive from natural sources (vitamins, flavonoids, anthocyanins, some mineral compounds).$^{16}$ There is an increasing interest in antioxidants, particularly in those intended to prevent the presumed deleterious effects of free radicals in the human body, as well as the deterioration of fats and other constituents of foodstuffs. ${ }^{8}$

\section{Synthetic Antioxidants}

Synthetic antioxidants are those antioxidants do not occur in na- 
ture but chemically synthesized and added to food products as preservatives to help prevent lipid oxidation. ${ }^{18}$ In order to have a standard antioxidant activity measurement system to compare with natural antioxidants and to be incorporated into food, synthetic antioxidants have been developed. These pure compounds are added to food so it can withstand various treatments and conditions as well as to prolong shelf life. Today, almost all processed foods have synthetic antioxidants incorporated, which are reported to be safe. ${ }^{19}$ Butylated hydroxytoluene (BHT) and butylated hydroxyanisole (BHA) are the most widely used chemical antioxidants. ${ }^{11}$ Inconsistent data's have been published regarding the allowable daily intake and exposure to some synthetic antioxidants. Furthermore, contradictory data are available relating to the effect of synthetic antioxidants on human health. Therefore, further research has to be performed in this regard. Some of the synthetic antioxidants currently permitted for use in foods include BHT, BHA, propyl gallate (PG), dodecyl gallate (DG) and tertiary butylhydroquinone (TBHQ). ${ }^{18,20}$

\section{Natural Antioxidants}

Natural antioxidants are those oxidants that are found in natural sources, such as fruits, vegetables and meats. ${ }^{21}$ Natural antioxidants can be found in all plant parts such as fruits, vegetables, nuts, seeds, leaves, roots and barks. ${ }^{21,22}$ There are several common natural antioxidants which are found in everyday foods, the most common of which being vitamin C (ascorbic acid), vitamin E (tocopherols), vitamin A (carotenoids), various polyphenols including flavonoids, anthocyanins, lycopene (a type of carotenoid), and coenzyme $\mathrm{Q}_{10}$, also known as Ubiquitin, which is a type of protein. ${ }^{8}$ Natural antioxidants are synthesized by plants (e.g. vitamins and other naturally-occurring chemicals in our food). Natural antioxidants are found in most fresh foods. ${ }^{23}$

\begin{tabular}{|ll}
\hline \multicolumn{2}{|l|}{ Table I. Sources of Some } \\
\hline Compounds & Natural Antioxidants ${ }^{22,25}$ \\
\hline Carotenoids & $\begin{array}{l}\text { Dark leafy vegetables, carrots, sweet potatoes, yams, } \\
\text { tomatoes, apricots, citrus fruits, kale, papaya }\end{array}$ \\
\hline Catechins & Green tea, berries, certain oilseeds \\
\hline Flavonoids (polyphenols) & $\begin{array}{l}\text { oilseeds, lettuce, berries, eggplants, peppers, citrus } \\
\text { fruits, cruciferous vegetables, onions, black tea }\end{array}$ \\
\hline Lycopene & Tomatoes, papaya, watermelon, guava, \\
\hline Phenolic acids & Oilseeds and certain oils, cereals, grains \\
\hline Vitamin C & $\begin{array}{l}\text { Fruits and vegetables, berries, citrus fruits, green } \\
\text { peppers, potatoes. }\end{array}$ \\
\hline VitaminE(tocopherols) & $\begin{array}{l}\text { Oilseed, palm oil, nuts, eggs, dairy products, whole } \\
\text { grains, vegetables, cereals, margarine, etc. }\end{array}$ \\
\hline Extracts & $\begin{array}{l}\text { Extract from green tea, rosemary, sage, clove, } \\
\text { oregano, thyme, oat, rice bran }\end{array}$ \\
\hline
\end{tabular}

\section{MAIN SOURCES OF NATURAL ANTIOXIDANTS FROM FOODS}

Plants provide rich natural antioxidants. Antioxidants are abundant in fruits and vegetables, as well as in other foods including nuts, grains and some meats, poultry and fish. ${ }^{9}$ Natural antioxidants are present in plants (Table 1), and this is why the basic source of these compounds for humans is plant-derived products. ${ }^{22}$ Fruits, vegetables and medicinal herbs are the richest sources of antioxidant compounds such as vitamins $A, C$ and $E$, $B$-carotene and important minerals. ${ }^{24}$ There are wide variations between the total phenolic contents of the different fruits or vegetables, or even for the same fruits or vegetables reported by different authors. ${ }^{20}$ The human antioxidant system is divided into two major groups, enzymatic antioxidants and non-enzymatic oxidants. ${ }^{25,26}$

\section{Enzymatic Antioxidants}

Enzymatic antioxidants further divided into primary and secondary enzymatic defenses. With regard to the primary defense, it is composed of three important enzymes that prevent the formation or neutralize free radicals: glutathione peroxidase, catalase and superoxide dismutase. ${ }^{26}$ The secondary enzymatic defense includes glutathione reductase and glucose-6-phosphate dehydrogenase. ${ }^{27,28}$ These two enzymes do not neutralize free radicals directly, however, they may contribute to the activity of other endogenous antioxidants.

\section{Non-Enzymatic Antioxidants}

The non-enzymatic antioxidants are actually the scavengers of ROS and reactive nitrogen species (RNS); these involve peptides (glutathione); vitamin $\mathrm{E}$ and $\mathrm{C}$ (inhibits oxidation of membrane lipid); nitrogen compounds such as uric acid, which is a natural scavenger of peroxynitrite in plasma; albumin; bilirubin; N-Acetylcysteine (NAC); melatonin which directly reacts with ROS and form disulfides. ${ }^{19,29,30}$

\section{ANTIOXIDANTS MECHANISM OF ACTION}

The possible mechanisms of action of antioxidants were first explored when it was recognized that substance with anti-oxidative activity is likely to be the one that itself readily oxidized. An antioxidant can be defined as: "any substance that, when present in low concentrations compared to that of an oxidizable substrate, delays or inbibits the oxidation of that substrate" ${ }^{31,32}$ A free radical can be defined as, "any molecular species capable of independent existence that contains an unpaired electron in an atomic orbital and capture electrons from other substances in order to neutralize themselves". ${ }^{33}$ The existence of an unpaired electron results in certain common properties shared by most of the radicals. ${ }^{23}$

Two principal mechanisms of action have been proposed for antioxidants. The first is a chain-breaking mechanism by which the primary antioxidants donate electrons to the free radicals present in the system, example lipid radicals. ${ }^{34}$ Chainbreaking antioxidants act by scavenging free radicals and donating hydrogen atoms. ${ }^{35}$ The second mechanism involves removal of ROS and RNS initiator by quenching chain initiator catalyst. ${ }^{36}$ Preventative antioxidants are generally metal chelators and reductants capable of sparing other antioxidants in vivo. ${ }^{35}$ These reactive species are capable of causing damage to the vital biological molecules such as deoxyribonucleic acid (DNA), proteins, carbo- 
- Indirect determination: the presence of free radicals causes the loss or appearance of a reagent and therefore, in the presence of an antioxidant, an increasing or decreasing in the signal is caused (oxygen radical absorbance capacity (ORAC) and ferric reducing ability of plasma (FRAP) methods) proportional to the antioxidant activity of the sample.

On the first stage of oxidation reaction from biological systems $\mathrm{RH}$ are formed radicals $\mathrm{R}^{-}$as a resultof abstraction of a hydrogen atom $\mathrm{H}^{-}$:

\section{Initiation Stage:}

(1) $\mathrm{RH} \rightarrow \mathrm{R}^{\cdot}+\mathrm{H}^{\cdot}$

(2) $\mathrm{R}^{\cdot} \rightarrow \mathrm{R}^{\cdot}+\mathrm{O}_{2} \rightarrow \mathrm{ROO}^{*}$

(3) $2 \mathrm{ROOH} \rightarrow \mathrm{ROO}^{*}+\mathrm{RO}^{*}+\mathrm{H}_{2} \mathrm{O}$

After initiation, propagation of the free radical chain occurs, in which molecule of oxygen from environment react with reactive radical species, resulting in formation of peroxides and peroxyl radical $\mathrm{ROO}^{-}$. These intermediates may further propagate free radical reactions:

\section{Propagation Stage:}

(1) $\mathrm{R}^{\cdot}+\mathrm{O}_{2} \rightarrow \mathrm{ROO}^{*}$

(2) $\mathrm{ROO}^{\circ}+\mathrm{RH} \rightarrow \mathrm{ROOH}+\mathrm{R}^{\circ}$

(3) $\mathrm{RO}+\mathrm{RH} \rightarrow \mathrm{ROH}+\mathrm{R}$

In the last stages, interaction of two radicals may lead to formation of non-radical adduct and termination of free radical chain:

\section{Termination Stage:}

(1) $\mathrm{R}^{\cdot}+\mathrm{R}^{\cdot} \rightarrow \mathrm{R}-\mathrm{R}$

(2) $\mathrm{R}^{\cdot}+\mathrm{ROO}^{\cdot} \rightarrow \mathrm{ROOR}$

(3) $\mathrm{ROO}^{*}+\mathrm{ROO}^{*} \rightarrow \mathrm{ROOR}+\mathrm{O}_{2}$

(4) Antioxidants $+\mathrm{O}_{2} \rightarrow$ Oxidized antioxidants $\mathrm{s}^{38,39}$

Antioxidants can slow lipid oxidation by inactivating or scavenging free radicals, thus inhibiting initiation and propagation reactions. ${ }^{32}$ The antioxidants function by the very simple and effective method of donating hydrogen atom to free radicals and thus terminating their life. ${ }^{9}$

\section{Methodologies for the Quantification of Antioxidant Activity}

The measurements of the antioxidant activity can be carried out based on the information we want to obtain:

- Direct determination: a radical is used as a quantification factor (since it produces an analytical signal). In this sense, the addition of the antioxidant, before or after the generation of the radical, causes a decreasing in the signal $\left(2,2^{\prime}\right.$-azino-bis(3-ethylbenzothiazoline-6-sulphonic acid $\left(\mathrm{ABTS}^{\cdot+}\right)$ or (2,2-diphenyl-1-picrylhydrazyl (DPPH) methods), which is proportional to the antioxidant activity of the sample.
In that way, it is necessary to mention the differences between the free radical stabilizing activity or antiradicalaria (indirect methods) and the antioxidant activity (direct methods), the first being completely determined by the reactivity of an antioxidant against free radicals, characterized by reaction speed, while the second measures the ability to retard oxidative processes. ${ }^{40}$ In this sense, the results of the antioxidant capacity measurement obtained by each of the methods do not always coincide, even among methods based on the same redox mechanism, there may be variations. Therefore, it is recommended that an assessment of the antioxidant capacity be carried out using more than one analytical technique and comparisons among results only be made when the same method has been used and samples have been obtained with the same solvents. ${ }^{41,42}$

In general, it has been suggested to combine FRAP and ABTS techniques. ${ }^{43}$ This is because the use of the FRAP technique in combination with others such as ABTS and DPPH, allows to evaluate different interactions of the antioxidant compounds, expanding the knowledge about them, which is relevant in the exploration of the antioxidant properties of nutraceutical products from natural sources or simply from some products included in the diet, such as fruits and vegetables. ${ }^{44}$ When two techniques are used, as mentioned above, is generally sought that through one of them, is possible to determine the antioxidant activity based on transfer reactions of one electron single electron transfer (SET) and on the other, this same property is determined based on a transfer reaction of a hydrogen atom transfer (HAT for its acronym in English) between an antioxidant and a free radical, allowing to evaluate the two mechanisms to extend the spectrum of the results obtained. ${ }^{45}$ In Figure 1, the HAT and SET mechanisms are showed.

Figure I. Mechanisms of Antioxidant Reacting with Free Radical: Single Electron Transfer

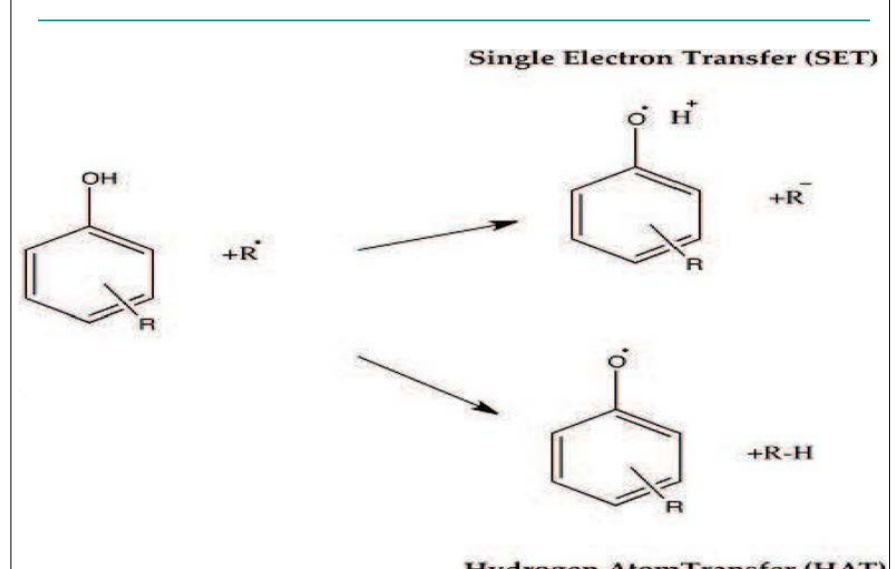
(SET) and Hydrogen Atom Transfer (HAT) 
Regarding the expression of results of antioxidant capacity, several methods (FRAP, ABTS and ORAC) express the results in $\mu \mathrm{mol}$ Trolox/g of sample on dry or wet basis (Trolox is a water-soluble analog of vitamin E). Likewise, these results can be expressed in terms of vitamin $C$ and $E$. In summary, a suitable method for the quantification of antioxidant activity should consider the electron transfer and hydrogen atoms reaction, establish the oxidation substrate, ensure that the substrate and how to induce oxidation, became relevant in terms of oxidative damage, be simple, have a mechanism and a denied endpoint, use available and affordable instrumentation, be reproducible, be adaptable to measure hydrophilic and lipophilic antioxidants, use different sources of free radicals with relevant biological characteristics and be adaptable for routine large-scale analyzes. ${ }^{46}$

This is increasingly important, since is known that no single method reflects the total antioxidant capacity of a sample, that is, its ability to act as an antioxidant of lipophilic and hydrophilic compounds through specific mechanisms, in addition to its reactivity against different species. ${ }^{47}$ In addition, is known that the antioxidant activity of a sample is not only given by the sum of the antioxidant capacities of the components present in it, but also depends on the synergistic and inhibitory effects that may exist among compounds. ${ }^{42}$ Table 2 summarizes the principal methods to quantify the antioxidant activity. ${ }^{48}$

\begin{tabular}{|ll|}
\hline $\begin{array}{l}\text { Table 2. Principles of the Most Common Methods Used to Quantify Invitro Antioxidant } \\
\text { Activity }\end{array}$ \\
\hline Principle & Method \\
\hline Metal reduction & Ferric ion-reducing antioxidant power (FRAP) \\
\hline $\begin{array}{l}\text { Peroxyl radical absorption } \\
\text { capacity }\end{array}$ & $\begin{array}{l}\text { Oxygen radical absorbance capacity (ORAC) } \\
\text { Total radical-trapping antioxidant parameter } \\
\text { (TRAP) }\end{array}$ \\
\hline $\begin{array}{l}\text { Hydroxyl radical absorption } \\
\text { capacity }\end{array}$ & Deoxyribose assay \\
\hline $\begin{array}{l}\text { Capacity for radicals' absorption } \\
\text { generated from certain organic } \\
\text { molecules }\end{array}$ & $\begin{array}{l}\text { 2,2'-azinobis acid (3-ethylbenzothiazolin)-6- } \\
\text { sulfonic (ABTS), radical 2,2 } \\
\text { diphenyl-I-picrilhydrazil (DPPH) }\end{array}$ \\
\hline $\begin{array}{l}\text { Quantification of products } \\
\text { generated during the lipid } \\
\text { peroxidation }\end{array}$ & $\begin{array}{l}\text { Tiobarbituric acid reactive species (TBARs), } \\
\text { oxidation of LDLs }\end{array}$ \\
\hline
\end{tabular}

\section{Synergism in Lipid Oxidation}

Synergism occurs when a mixture of antioxidants produces a more pronounced activity than the sum of the activities of the individual antioxidants when used separately. Synergism improves the efficiency of antioxidants. Synergist antioxidants can be classified as oxygen scavengers or chelators. ${ }^{30}$ To have maximum efficiency, primary antioxidants are often used in combination withother phenolic antioxidants, or with various metal chelating agents.

\section{Kinds of Metal Chelators and Free Radicals}

Metal chelators deactivate trace metals that are free or salts of fatty acids by the formation of complex ion or coordination compounds like phosphoric acid, citric acid, ascorbic acid and ethylenediaminetetraacetate (EDTA). ${ }^{1}$ Antioxidants normally neutralize the free radicals by being oxidized themselves and act as reducing agents such as thiols, ascorbic acid, or polyphenols. ${ }^{33}$

A free radical can be defined as any molecular species capable of independent existence that contains an unpaired electron in an atomic orbital. The presence of an unpaired electron results in certain common properties that are shared by most radicals. Many radicals are unstable and highly reactive. They can either donate an electron to or accept an electron from other molecules, therefore behaving as oxidants or reductants. Free radicals attack important macromolecules leading to cell damage and homeostatic disruption. Targets of free radicals include all kinds of molecules in the body. Among them, lipids, nucleic acids, and proteins are the major targets. Free radical formation occurs continuously in the cells as a consequence of both enzymatic and non-enzymatic reactions. Enzymatic reactions, which serve as source of free radicals, include those involved in the respiratory chain, in phagocytosis, in prostaglandin synthesis, and in the cytochrome P-450 system. ${ }^{49}$ Free radicals can also be formed in nonenzymatic reactions of oxygen with organic compounds as well as those initiated by ionizing reactions.

In a nutshell, free radicals reactive oxygen species and reactive nitrogen species are generated by our body by various endogenous systems, exposure to different physiochemical conditions or pathological states (Figure 2). A balance between free radicals and antioxidants is necessary for proper physiological function. If free radicals overwhelm the body's ability to regulate them, a condition known as oxidative stress ensues. Free radicals thus adversely alter lipids, proteins, and DNA and trigger a number of human diseases. ${ }^{29}$ Hence application of external source of antioxidants can assist in coping this oxidative stress. Synthetic antioxidants such as butylated hydroxytoluene and butylated hydroxyanisole have recently been reported to be dangerous for human health. Thus, the search for effective, nontoxic natural compounds with antioxidative activity has been intensified in recent years. $^{49}$

Figure 2. Sources of Free Radicals and Its Consequences in Human Body ${ }^{23}$

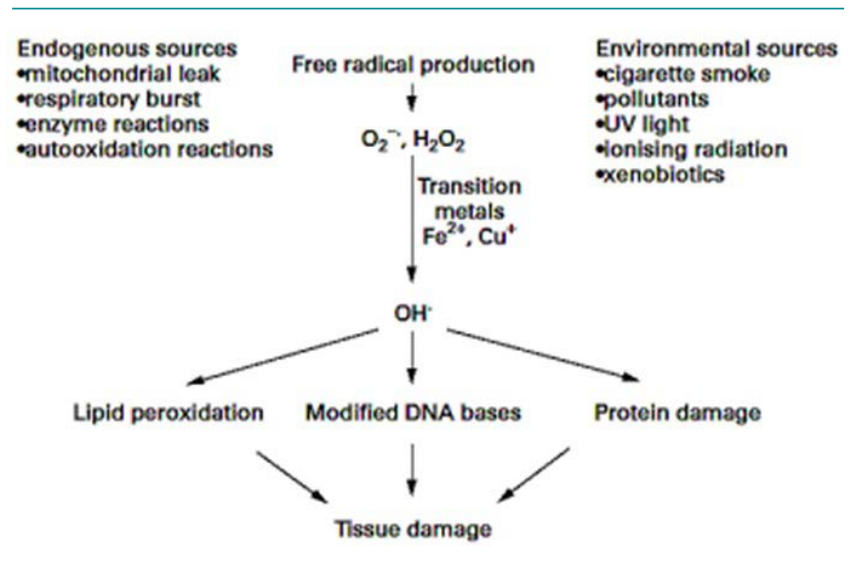




\section{PROCESSING OF ANTIOXIDANTS}

Although antioxidants are abundant in nature, only a limited number of raw materials such as vegetable oils and fats and rosemary leaves are used for manufacturing extracts with antioxidant activity. ${ }^{50}$ The demand for natural antioxidants resulted in a reduced use of synthetic antioxidants as they may result in toxicity, carcinogenicity or hepatotoxicity in human body. ${ }^{51}$ Since synthetic antioxidants including BHT may cause side effects to human health, it is presumed to be unsafe for consumption and/or for medical purposes. ${ }^{42}$ Thus, research's has been conducted in minimizing synthetic antioxidants undesirable health consequences.

Recent study's shows that synthesis of natural antioxidants from fruit and vegetable waste has gained a great attention. Processing of fruits, vegetables, and oilseeds result in high amounts of waste materials such as peels, seeds, stones, and oilseed meals. ${ }^{43}$ Disposal of these materials usually represents a problem that is further aggravated by legal restrictions. ${ }^{20}$ Moreover, valuable nutrients contained in agro-industrial wastes are lost. Thus, new aspects concerning the use of these wastes as by-products for further exploitation on the production of food additives or supplements with high nutritional value have gained increasing interest because these are high-value products and their recovery may be economically attractive. ${ }^{43}$

Fruit, vegetable, and oilseed processing result in various amounts of by-products depending on the raw material. According to Oreopoulou $\mathrm{V}$ et $\mathrm{al}^{43}$ out of the total fruits and vegetables processed worldwide almost half of it is estimated to be discarded as a waste presented some typical yields of antioxidant content in various fruit and vegetable by-products Table 3.

\begin{tabular}{|c|c|c|}
\hline By-product & $\begin{array}{l}\text { Phenol content } \\
\text { (g/kg dry matter) }\end{array}$ & References \\
\hline Apple pomace & 2.4 & 44 \\
\hline \multirow[t]{2}{*}{ Orange peel } & $1.8^{\mathrm{a}}$ & 45 \\
\hline & $2.4^{b}$ & 46 \\
\hline \multirow[t]{2}{*}{ Lemon peel } & $13.3^{c}$ & 47 \\
\hline & $1.9^{\mathrm{a}}$ & 45 \\
\hline \multirow[t]{2}{*}{ Grapefruit peel } & $1.6^{\mathrm{a}}$ & 45 \\
\hline & $2.4^{\mathrm{d}}$ & 46 \\
\hline Grape pomce & $13.8^{e}$ & 48 \\
\hline Potato peel & $7.8^{8}$ & 49 \\
\hline Red onion scale & $105.5^{f}$ & 49 \\
\hline Sunflower hulls & $97.5^{f}$ & 49 \\
\hline Buckwheat hulls & $39.0^{f}$ & 49 \\
\hline Durum wheat bran & $27.7^{8}$ & 50 \\
\hline Oat hulls & 0.6 & 51 \\
\hline \multicolumn{3}{|c|}{$\begin{array}{l}\text { a-In fresh peel, expressed as } g=k g \text { of fresh fruit; b-Hesperidin }(g=k g) \text { in the } \\
\text { fresh fruit; c-Flavonoids (eriocitrin and hesperidin); d-Naringin }(g=k g) \text { in the } \\
\text { fresh fruit; e-Expressed as gallic acid; f-Expressed as ferulic acid; } g \text {-Phenolic } \\
\text { acids analyzed by HPLC }\end{array}$} \\
\hline
\end{tabular}

Agricultural and industrial residues are attractive sources of natural antioxidants. ${ }^{50}$ It had been previously reported that these wastes and by-products of fruits and vegetables in food processing industry are an abundant source of antioxidant polyphenols or phenolic compounds. Some studies have already been done on by-products, which could be potential sources of antioxidants. ${ }^{20}$ These peels and pomace are a source of sugars, minerals and organic acids, dietary fibers and phenolic compounds which have a wide range of actions including antioxidant, antimutagenic, cardio preventive, antibacterial and antiviral activities. ${ }^{49}$ Use of waste as a source of polyphenols and antioxidants may have considerable economic benefit to food processing industries. Therefore a cheap, efficient and environmentally sound utilization of these huge agro-industrial wastes is needed. ${ }^{52}$

Antioxidants are recovered from different plant residuals by extraction process. Using extraction process crude extract of bioactive compounds will be recovered from fruit by-products. ${ }^{42}$ There is different extraction process available so far. Solvent extraction, mechanical procedures, molecular distillation, heating in oil at high temperature and supercritical fluid extraction are among the methods used for extraction of antioxidants. ${ }^{40}$ Figure 3 shows the utilization of agro-industrial by-products for extraction of antioxidants using organic solvent or water.

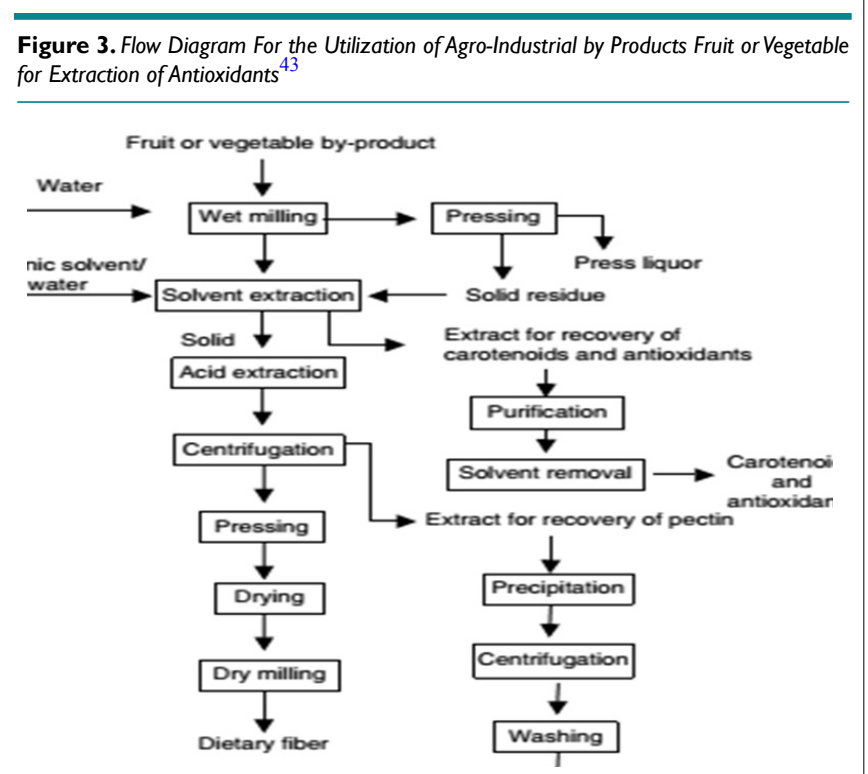

Usually valuable natural materials have been extracted with organic solvents. However, some of them are toxic, and the extraction conditions are often severe. For this reason, in solvent extraction a food grade solvent is recommended to be used..$^{53}$ The effects of different parameters (conditions of the preparation of peel samples, repeated extraction, organic solvents used and their concentration, temperature, etc.) on the extraction process were investigated by different authors. ${ }^{54}$ To this point, significant research has been done on the polyphenols obtained from grape marc, soya bean seed coat, potato peels, sugar beet pulp, etc. Besides these, search for newer sources of natural antioxidants from economical materials, agricultural wastes is hot area of research in recent years. ${ }^{20}$ 


\section{APPLICATIONS OF ANTIOXIDANTS}

\section{Role of Antioxidants in Food Industries}

Cells are protected against oxidative stress by an interacting network of antioxidant enzymes. ${ }^{17}$ The superoxide released by processes such as oxidative phosphorylation is first converted to hydrogen peroxide and then further reduced to give water. This detoxification pathway is the result of multiple enzymes, with superoxide dismutase's catalyzing the first step and then catalases and various peroxidases removing hydrogen peroxide. ${ }^{19}$ People in today's world want to eat healthier food to stay fit and this is being achieved by incorporating unsaturated and polyunsaturated fats in the food products being marketed. As the human lifestyle and also its view towards food are changing thus there is an increased shift observed from convenient foods to ready toeat product category. For this there is need of certain potential health protecting factors named as antioxidants. ${ }^{55}$

Antioxidants, both natural and synthetic, have a wide applications in food industries as they are used as food additives in fats and oils to help prolong the shelf life and appearance of many foodstuffs. ${ }^{23}$ Thus, efforts are being made to reduce oxidation by increasing addition of antioxidants to food. Lipid oxidation is a major cause of quality deterioration in many types of natural and processed foods. It is usually undesirable in most foods because it leads to the development of rancidity and potentially toxic reaction products. One of the most effective means of retarding lipid oxidation in foods is to incorporate antioxidants as preservatives. ${ }^{23,56}$ Synthetic phenolic antioxidants such as propyl gallate (PG, E310), tertiary butylhydroquinone (TBHQ), butylated hydroxyanisole (BHA, E320) and butylated hydroxytoluene (BHT, E321) effectively inhibit oxidation. For example, chelating agents such as EDTA, can bind metals reducing their contribution to the oxidation process. ${ }^{23,57}$

The search for effective methods to retard oxidative processes in meat and meat products has led researchers to investigate natural antioxidants. Addition of antioxidants to meat and meat products is known to be effective in metmyoglobin formation and lipid oxidation. ${ }^{58}$ These preservatives include plant phenols as natural antioxidants such as vitamins (ascorbic acid [AA] and $\alpha$-tocopherol (E306)), many herbs and spices (rosemary, thyme, oregano, sage, basil, pepper, clove, cinnamon, and nutmeg), and plant extracts (tea and grape seed) contain antioxidant components thus imparting antioxidant properties to the compound. ${ }^{55,57}$

While use of synthetic antioxidants (such as butylated hydroxytoluene and butylated hydroxyanisole) to maintain the quality of ready-to-eat food products has become common place, consumer concern regarding their safety has motivated the food industry to seek natural antioxidants. ${ }^{57}$ The antioxidants obtained from plants are more functional towards improving the shelf life of food products and providing health promotion when compared to materials whose antioxidants have been removed during processing. ${ }^{23}$ Thus, current researches are under investigation on the various extraction technologies and processing for plant extracts to be used as antioxidant additives for food industries.

\section{Medical Application of Antioxidants}

Antioxidants have important preventive roles not only on undesirable changes in the flavor and nutritional quality of food, but also on tissue damage in various human diseases. They are effective in prevention of degenerative illnesses, such as different types of cancers, cardiovascular and neurological diseases, cataracts and oxidative stress dysfunctions. ${ }^{6,59}$ Chronic diseases such as arteriosclerosis and cancer, which are the leading causes of death in the Western world, are likely to be mediated by free radical and lipid per oxidation mechanisms. ${ }^{35}$ Antioxidants have been investigated and reported to play a specific role in the treatment of these diseases/disorders. ${ }^{55}$

Polyphenols are the most significant compounds for the antioxidant properties of plant raw materials. Medicinal plant parts are commonly rich in phenolic compounds, such as flavonoids, phenolic acids, stilbenes, tannins, coumarins, lignans and lignins. These compounds have multiple biological effects including antioxidant activity. ${ }^{6}$

Various research studies conducted so far have confirmed the role of antioxidants, viz., lanthanides, selenium, flavonoids, lycopene and glutathione as anti-cancerous compounds in bio-coordination chemistry. Recent developments in medicinal chemistry have become crucial for improving the design of the compound, reducing toxic side effects and understanding their mechanism of action. ${ }^{55}$ Oxidants may play role in many diseases. ${ }^{60}$ In the last decades, several epidemiological studies have shown that dietary intake of foods rich in natural antioxidants was correlated with reduced risk of coronary heart disease. ${ }^{61} \mathrm{Di}$ etary and natural antioxidants present in foods and other biological materials have attracted considerable interest because of their presumed safety and potential nutritional and therapeutic or health effects. ${ }^{62,63}$

\section{Industrial Application}

Antioxidants are frequently added to industrial products. A common use is as stabilizers in fuels and lubricants to prevent oxidation, and in gasoline to prevent the polymerization that leads to the formation of engine-fouling residues. They are widely used to prevent the oxidative degradation of polymers such as rubbers, plastics and adhesives that causes a loss of strength and flexibility in these materials. ${ }^{57}$

Nowadays, most food and pharmaceutical products contain synthetic antioxidants. These compounds are added to food in order to prolong product shelf life, mainly by preventing the oxidation of unsaturated double bonds of fatty acids. In pharmaceutical products antioxidants are added to enhance the stability of therapeutic agents that are susceptible to chemical degradation by oxidation. ${ }^{64}$ 
Applications of plant extracts with antioxidant activity in food processing were investigated and more are under investigation in their uses for health paybacks, conservation processes improvement and shelf-life extension. The plant source and industrially recovered antioxidants can be incorporated into various food matrices including meats, oils, fruits, vegetables, spices and condiments, root crops, pulses and cereal products. Research and development on the application of plant origin extracts with respect to antioxidant activity in food processing requires outcomes for amble sources of antioxidants, innovative methods of extraction technologies, application techniques with their respective thresh hold level, successive effects and regulatory aspects to improve their oxidative stability. ${ }^{63}$

\section{NATURAL ANTIOXIDANTS UTILIZATION IN THE AFRICAN CONTEXT}

Being located within the tropical and sub-tropical climates has made Africa rich in enormous biodiversity resources. In Africa there is a vast amount of vegetables, fruits and mushrooms which are consumed for food and their medicinal purposes. ${ }^{65,66}$ The use of traditional medicines prepared from plant sources is well known in different parts of the continent. This plant sources are widely used for preparing remedies in the form of alternative medicine. Antioxidants are particularly important among the numerous compounds found in plants because they might serve as precursors for the development of novel drugs. ${ }^{11}$ Africa has many diverse varieties of plant resources like fruits and vegetables, spices and many other types of fruits and vegetables, which can be processed and utilized as a source of antioxidants. ${ }^{65,67}$ Studied and evaluated some of African medicinal plants for their antioxidant activities. According to their study, considering the enormous biodiversity resource that Africa has, the attention given to the utilization of these resources is still rather very low.

The utilization of industrially processed natural antioxidants in the Africa context is very limited compared to utilization of imported synthetic antioxidants in the area of food processing industries application. ${ }^{36}$ Consequently, there is a need for the stakeholders to engage and give a due attention towards the valuable plant resources present in the African continent. Top urgently, need to start in evaluating the potential utilization and processing of its enormous biodiversity resources as a potential source for natural antioxidants manufacturing in to the growing food industry. ${ }^{67}$ This will help Africa to save a huge cost that has been invested for import of synthetic antioxidant in food industries and help the continent in a fight to disease and poverty. The use of natural antioxidants in food products of plant and animal origin is one of the new and intensive research areas.

Ethiopia is one of the major countries with a wide distribution and high potential for plant sources. Even though few studies have reported the nutritional value of various indigenous food ingredients consumed in Ethiopia, only limited information is available regarding their phenolic content and health beneficial properties. ${ }^{68}$ Furthermore, there is shortage of organized information regarding antioxidants and related issues in Ethiopia. ${ }^{69}$ Moringa tree (Moringa Stenopetala) is among the medicinal plant as- sociated with naturally occurring antioxidants. Moringa stenopetala is widely used for treatment of high blood pressure, diabetes and also heart problems in the country. However, nowadays there are some emerging research works on antioxidant in Ethiopia. ${ }^{69}$

\section{INFLUENCE OF NATURAL ANTIOXIDANTS IN HUMAN HEALTH}

Normal molecules in the body have two (a paired group) electrons in their outer shell. A molecule with a single electron (unpaired) in its outer shell is called a free radical. Antioxidants are important in living organisms as well as in food because they may delay or stop formation of these free radicals by giving hydrogen atoms or scavenging them. ${ }^{11}$ The destructive effects of free radicals can be prevented with the addition of antioxidants in the diet or by antioxidant supplements. ${ }^{70}$

When a specific antioxidant meets a free radical in the bloodstream at its appropriate activity site, it naturally combines with it and coverts the free radical to harmless water and oxygen. As a result, as antioxidant increases due to the supplementation of higher amounts of a greater variety of anti-oxidants, cellular damage lessens and performance and health improves. ${ }^{9}$

The antioxidants that have caused health problems, for some people, are primarily synthetic. The most problematic antioxidants appear to be BHA, BHT and TBHQ, with gallates in second place and have been used in food products, with some restrictions, since the late 1950s. Asthma, angioedema, dermatitis, excessive sweating, joint pains, stomach and eye problems are among the health problems in humans that have been linked with adverse reactions to BHA, BHT and/or TBHQ. ${ }^{23,71} \mathrm{New}$ data indicating that the synthetic antioxidants used in the industry could have carcinogenic effects on human cells resurface every year. Thus, the search for effective, non-toxic natural compounds with antioxidant activity has been intensified in recent years. ${ }^{64,72,73}$ Since there are recent studies on the effect of antioxidants on human health reveal that some of currently available data's may not be true as they supposed or contradict with current findings. Thus, the positive effect of antioxidants in human health should be investigated intensively. ${ }^{74}$

\section{FUTURE PERSPECTIVES ON NATURAL ANTIOXIDANTS TO REDUCE DISEASE BURDEN IN AFRICA /}

During the past decades a lot of research has been carried out around antioxidants and their effects on health. However, there is still a lack of a standard procedure to determine antioxidant activity across the majority of matrixes in order to produce consistent and undoubted results. The published results so far are conflicting and difficult to compare between each other. The antioxidant limitations and metabolism still pose a challenge to future research in this field, and researchers must try and overcome these drawbacks. ${ }^{19}$ The level of intake (threshold level) of antioxidant nutrients desirable for optimal nutrition is still an open question, and there is little information on antioxidant bioavailability in vivo in humans. ${ }^{40,75}$ Furthermore, to develop a more complete framework for the relevance of antioxidants for the ex- 
4. Eboh AS. Biochemistry of free radicals and antioxidants. Sch. Acad. J. Biosci. 2014; 2(2): 110-118. future studies should consider the full range of available antioxidants, their possible interactions, their environmental availability, and the potential for inter individual differences in anti-oxidant intake and uptake. ${ }^{2,76}$ The current African traditional practices for food and medicines utilization of exotic plant resources as antioxidants shall be supported by evidence based research and development to support millions of Africans who has the resources in hand. Extraction and processing of antioxidants from African plant resources are expected to come via turning research into impact, and establishment of functional and nutraceutical industries for the same purpose to save millions from the current chaos.

\section{CONCLUSION}

Current research carried-out in the field of increases knowledge about naturally healthy compounds that are available in agricultural produces. Advance research has to performed on processing and utilization of agricultural and industrial by-products as a potential source for extraction of antioxidants. Investigations should be done on determination of threshold level of intake for antioxidants and related possible side effects.

The present review likewise provides a brief overview on oxidative stress mediated cellular damages and role of natural dietary antioxidants as functional foods in the management of human diseases. The imminent research focus can identify possible application of natural antioxidants, the most important; they can recognize them as an alternative to replace chemical synthesized antioxidants used in food industry improving the market of natural products.

The forthcoming research can focus on promoting the use of natural extracts and fulfilling consumer demands for healthier foods. Natural antioxidants use in food products will increase quality and added value. Hence, novel methodologies of extraction, purification, identification and quantification of natural antioxidants using environmentally friendly techniques need to be developed to improve the extraction yields and market value of natural products.

\section{CONFLICTS OF INTEREST |}

The authors declare that they have no conflicts of interest.

\section{REFERENCES}

1. Gautam RS, Thul M, Kumar NS. Antioxidants: Types, properties and mechanism. 2010;1-8.

2. Kumar S. The importance of antioxidants and their role in pharmaceutical science - A review. Asian Journal of Research in Chemistry and Pharmaceutical Sciences. 2014; 1(1): 27-44.

3. Nithyanand P, Balakrishnan D, Kandasamy D. A review on Antioxidant activity of marine organisms. International Journal of ChemTech Research. 2014; 6(7): 3431-3436.
5. Esan YO, Sade OO, Victor EN, Oluranti OO. Functional and antioxidant properties of raw and popped Amaranth (Amaranthus cruentus) seeds flour. Annals Food Science and Technology. 2018; 19(2). 399-408.

6. Singh L. Suruchi S, Sharma SK. A review on medicinal plants having antioxidant potential. Indian Journal of Research in Pharmacy and Biotechnology. 2013; 1(3): 404-409.

7. Partap S, Pandey S. A review on Herbal Antioxidants. Journal of Pharmacognosy and Phytochemistry. 2012; 1(4): 26-37.

8. Yadav A, Kumar R, Yadav A, et al. Antioxidants and its functions in human body - A Review. Res. Environ. Life Sci. 2016; 9(11): 1328-1331.

9. Hamid AA, Aiyelaagbe OO, Usman LA, Ameen OM, Lawal A. Antioxidants: Its medicinal and pharmacological applications. African Journal of Pure and Applied Chemistry. 2010; 4(8): 142-151.

10. Sikora E, Cieślik E, Topolska K. The Sources of Natural Antioxidants. Acta Sci. Pol. Technol. Aliment. 2008; 7(1): 5-17.

11. Pérez JAM, Aguilar TAF. Chemistry of natural antioxidants and studies performed with different plants collected in Mexico. In: Morales-González JA (ed). Oxidative Stress and Chronic Degenerative Diseases - A Role for Antioxidants. London, UK: Intech. 2013. 59-81. doi: 10.5772/52247

12. Pisarikova B, Zraly Z, Kracmar S, Trckova M, Herzig I. The use of amaranth (Genus Amaranthus L.) in the diets for broiler chickens. Veterinarni Medicina. 2006; 51(7): 399-407. doi: 10.17221/5560-VETMED

13. Dimitrios B. Sources of natural phenolic antioxidants. Trends in Food Science \& Technology. 2006; 17(9): 505-512. doi: 10.1016/j. tifs.2006.04.004

14. Boskou D, Blekas G, Tsimidou M. Phenolic compounds in olive and olives. Current Topics in Nutracentical Research. 2005; 3(2): 125-136.

15. Ortega-Ramírez L, Rodríguez-García I, Leyva J, et al. Potential of medicinal plants as antimicro-bial and antioxidant agents in food industry: A hypothesis. J Food Sci. 2014; 79(2): R129-R137. doi: $10.1111 / 1750-3841.12341$

16. Percival M. Antioxidants. Clinical Nutrition Insights. 1996. Advanced Nutrition Publications, Inc., Revised 1998.

17. Jacob RA. The integrated antioxidant sysytem. Nutrition Research. 1995. 15(5): 755-766. doi: 10.1016/0271-5317(95)00041-G

18. Shahidi F, Wanasundara PK. Phenolic antioxidants. CritRev Food 
Sci Nutr. 1992; 32(1): 67-103. doi: 10.1080/10408399209527581

19. Carocho M, Ferreira IC. A review on antioxidants, prooxidants and related controversy: natural and synthetic compounds, screening and analysis methodologies and future perspectives. Food Chem Toxicol. 2013; 51: 15-25. doi: 10.1016/j.fct.2012.09.021

20. Mohdali AAA. Evaluation of Some Food Processing by-Products as Sources for Natural Antioxidants [master's thesis]. Chicago, IL, USA: Technical University of Berlin; 2010.

21. Grozea, M.B.a.I., Antioxidant (Antiradical) Compounds. Journal of Bioequivalence \& Bioavailability, 2012; 4(6): doi: 10.4172/ jbb.10000e18

22. Akbarirad H, Ardabili GA, Kazemeini SM, Khaneghah MA. An overview on some of important sources of natural antioxidants. International Food Research Journal. 2016; 23(3): 928-933.

23. Anbudhasan P, Surendraraj A, Karkuzhali S, Sathishkumaran P. Natural antioxidants and its benefits. International Journal of Food and Nutritional Sciences. 2014; 3(6): 225-232.

24. Sies H, Stahl W, Sundquist AR. Antioxidant functions of vitamins, vitamins $\mathrm{E}$ and $\mathrm{C}$, beta-carotene, and other carotenoids. Ann N Y Acad Sci. 1992. 669: 7-20.

25. Balasundram N, Sundram K, Samman S. Phenolic compounds in plants and agri-industrial by-products: Antioxidant activity, occurrence, and potential uses. Food Chemistry. 2006; 99: 191-203. doi: 10.1016/j.foodchem.2005.07.042

26. Rahman K. Studies on free radicals, antioxidants, and co-factors. Clin Interv Aging. 2007; 2(2): 219-236.

27. Ratnam DV, Ankola DD, Bhardwaj V, Sahana DK, Kumar MN. Role of antioxidants in prophylaxis and therapy: A pharmaceutical perspective. J Control Release. 2006; 113: 189-207. doi: 10.1016/j.jconrel.2006.04.015

28. Gamble PE, Burke JJ. Effect of water stress on the chloroplast antioxidant system: I. Alterations in glutathione reductase activity. Plant Physiol. 1984; 76: 615-621.

29. Noori S. An Overview of Oxidative Stress and Antioxidant Defensive System. Open Access Scientific Reports. 2012; 1: doi: 10.4172 /scientificreports.413

30. Brodowska KM. Natural flavonoids: Classification, potential role, and application of flavonoid analogues. European Journal of Biological Research. 2017; 7: 109-110.

31. Arjmand A. Antioxidant Activity of Pomegranate (Punica Granatum L.) Polyphenols and their Stability in Probiotic Yoghurt [master's thesis]. Punjab, India: RMIT University; 2011.

32. Rosenblat M, Aviram M. Antioxidative properties of pome- granate: in vitro studies. In: Seeram NP, Schulman RN, Heber D (eds). Pomegranates: Ancient Roots to Modern Medicine. . New York, USA: CRC Press. 2006. 31-43.

33. Halliwell B, Gutteridge JMC. Free Radicals in Biology and Medicine. Oxford, England, UK: Clarendon Press. 1999.

34. Mahantesh SP, Gangawane AK, Patil CS. Free radicals, antioxidants, diseases and phytomedicines in human health: Future prospects. World Research Journal of Medicinal \& Aromatic Plants. 2012; 1(1): 6-10.

35. De Beer D, Joubert E, Gelderblom WCA, Manley M. Phenolic compounds: A review of their possible role as in vivo antioxidants of wine. South African Journal for Enology and Viticulture. 2002; 23(2): 48-61. doi: 10.21548/23-2-2155

36. Terefe AA. Extraction and Characterization of Antioxidant from Orange Peels [master's thesis]. Addis Ababa, Ethiopia: Addis Ababa University; 2016. 147.

37. Young IS, Woodside JV. Antioxidants in health and disease. J Clin Pathol. 2001; 54: 176-186. doi: 10.1136/jcp.54.3.176

38. Polumbryk M, Ivanov S, Polumbryk O. Antioxidants in food systems. Mechanism of action. Ukrainian Journal of Food Science. 2013; 1(1): 15-40.

39. Ingold KU. Inhibition of the autoxidation of organic substances in the liquid phase. Chemical Reviews. 1996; 61: 563-584. doi: $10.1021 / \operatorname{cr} 60214 \mathrm{a} 002$

40. Stanley DJC. Report on Antioxidants: Scientific basis, regulatory aspects and industry perspectives. International Life Sciences Institute (ILSI). 2000.

41. Nantitanon W, Yotsawimonwat S, Okonogi S. Factors influencing antioxidant activities and total phenolic content of guava leaf extract. LWT - Food Science and Technology. 2010; 43(7): 10951103. doi: 10.1016/j.lwt.2010.02.015

42. Kamaludin NHI, Mun LS, Sa'adi RA. Evaluation of antioxidant activity of some tropical fruit peel extracts: Extraction conditions optimization of rambutan peel extract. ARPN Journal of Engineering and Applied Sciences. 2016; 11(3): 1623-1631.

43. Oreopoulou V, Tzia C. Utilization of plant by-products for the recovery of prteins, dietery fibers, antioxidants and colorants. In: Oreopoulou V, Russ W (eds). Utilization of By-Products and Treatment of Waste in the Food Industry. New York, USA: Springer. 2007. 209-232. doi: 10.1007/978-0-387-35766-9_11

44. Schieber A, Hilt P, Streker P, et al. A new process for the combined recovery of pectin and phenolic compounds from apple pomace. Innovative Food Science and Emerging Technologies. 2003; 4: 99-107. doi: 10.1016/S1466-8564(02)00087-5 
59. Mbata TI. Antioxidant nutrients: Beneficial or harmful. Internet Journal of Food Safety. 2000; 7: 29-33.

$\mathrm{L}$, et al. Application of functional citrus by-products to meat products. Trends Food Sci. Tech. 2004; 15: 176-185. doi: 10.1016/j. tifs.2003.08.007

46. Braddock RJ. By-products of citrus fruit. Food Technollogy. 1995; 49(9): 74.

47. Coll MD, Almela LC, Sánchez JL, Tomás-Barberán FA. Recovery of flavanones from wastes of industrially processed lemons. Z. Lebenm. Unters. F. A. 1998; 206(6): 404-407. doi: 10.1007/ s002170050282

48. Louli V, Ragoussis N, Magoulas K. Recovery of phenolic antioxidants from wine industry by-products. Bioresour Technol. 2004; 92: 201-208. doi: 10.1016/j.biortech.2003.06.002

49. Velioglu YS, Mazza G, Gao L, Oomah BD. Antioxidant activity and total phenolics in selected fruits, vegetables, and grain products. J. Agric. Food Chem. 1998; 46: 4113-4117. doi: 10.1021/ jf9801973

50. Moure A, Cruz JM, Franco Ruiz DJ, et al. Natural antioxidants from residual sources. Food Chemistry. 2001; 72: 145-171. doi: 10.1016/S0308-8146(00)00223-5

51. Emmons CL, Peterson DM. Antioxidant activity and phenolic contents of oat groats and hulls. Cereal Chem. 1999; 76(6): 902906. doi: 10.1094/CCHEM.1999.76.6.902

52. Immanuel G, Singh S. Extraction of antioxidants from fruit peels and its utilization in paneer. Journal of Food processing and technology. 2014; 5: 349. doi: 10.4172/2157-7110.1000349

53. Diankov S, Karsheva M, Hinkov I. Extraction of natural antioxidants from lemon peels. Kinetics and antioxidant capacity. Journal of the University of Chemical Technology and Metallurgy. 2011; 46(3): 315-319.

54. Mariana-Atena P, Diana M, Dogaru D, et al. Processing and storage impact on the antioxidant properties and color quality of some low sugar fruit jams. Romanian Biotechnological Letters. 2011; 16(5): 6504-6512.

55. Sindhi V, Guptha V, Sharma K, et al. Potential applications of antioxidants : A review. journal of pharmacy research. 2013; 7: 828835. doi: 10.1016/j.jopr.2013.10.001

56. Mishra R, Bisht SS. Antioxidants and their charecterization. Journal of Pharmacy Research. 2011; 4(8): 2744-2746.

57. Arshiya S. The antioxidant effect of certain fruits: A review. Journal of pharmaceutical sciences and research. 2013; 5: 265-268.

58. Dolatowski ZJ, Karwowska M. The effect of natural antioxidants on the oxidative processes in beef. Acta Sci. Pol. Technol. Aliment. 2007; 6: 17-25.
60. Bast A. Antioxidants as drugs. 2010.

61. Yordi EG, Pérez EM, Matos MJ, Uriarte E. Antioxidant and pro-oxidant effects of polyphenolic compounds and structureactivity relationship evidence. In: Bouayed J (ed). Nutrition, WellBeing and Health. London, UK: Intech. 2012. doi: 10.5772/29471

62. Jongen W. Fruit and Vegitable Processing: Improving Quality. Sawston, Cambridge: Woodhead Publishing Ltd. 2000.

63. Mandal S, Yadav S, Yadav S, Nema RK. Antioxidants: A Review. Journal of Chemical and Pharmacentical Research. 2009; 1(1): 102-104.

64. Shebis Y, Iluz D, Kinel-Tahan Y, Dubinsky Z, Yehoshua Y. Natural antioxidants: Function and sources. 2013; 4: 643-649. doi: $10.4236 /$ fns. 2013.46083

65. Hamzah RU, Jigam AA, Makun HA, Egwim EC. Antioxidant properties of selected African vegetables, fruits and mushrooms: A review. In: Makun HA (ed). Mycotoxin and Food Safety in Developing Countries. London, UK: Intech. 2013.

66. Konan Y, Witabouna KM, Bassirou B, Kagoyire K. Antioxidant activity and total phenolic content of nine plants from côte d'Ivoire (West Africa). Journal of Applied Pharmaceutical Science. 2014; 4(8): 36-41. doi: 10.7324/JAPS.2014.40807

67. Atawodi SE. Antioxidant potential of African medicinal plants. African Journal of Biotechnology. 2005; 4(2): 128-133.

68. Forsido SF, Rupasinghe HP, Astatkie T. Antioxidant capacity, total phenolics and nutritional content in selected Ethiopian staple food ingredients. Int J Food Sci Nutr. 2013; 64(8): 915-920. doi: 10.3109/09637486.2013.806448

69. Dadi DW, Emire SA, Hagos AD, Jong-Bang E. Improvement of yield of bioactive compounds and antioxidant activity of moringa stenopetala leaves by optimizing ultrasonic-assisted extraction. Journal of Food Science and Technology. 2018; 7(3): 1-11.

70. Réblová Z. Effect of temperature on the antioxidant activity of phenolic acids. Czech J. Food Sci. 2012; 30: 171-177. doi: 10.17221/57/2011-CJFS

71. Wahlqvist ML. Antioxidant relevance to human health. Asia Pac J Clin Nut. 2013; 22: 171-176. doi: 10.6133/apjcn.2013.22.2.21

72. Sharma SK, Gupta VK. Plants as natural antioxidants. Natural Product Radiance. 2006; 5: 326-334.

73. Sen S, Chakrabort R, Sridhar C, Reddy YSR, Biplab De. Free radicals, antioxidants, diseases and phytomedicines: Current status and future prospect. International Journal of Pharmacentical Sci- 
ences Review and Research. 2010; 3(1): 91-100.

74. Salehi B, Martorell M, Arbiser JL, et al. Antioxidants: Positive or Negative Actors? Biomolecules. 2018; 8: 124. doi: 10.3390/ biom 8040124

75. Zuo Y, Wang C, Zhan J. Separation, characterization and quantitation of benzoic and phenolic antioxidants in American cranberry fruit by GC-MS. J. Agric. Food Chem. 2002; 50(13): 37893794. doi: 10.1021/jf020055f

76. Gajula D, Verghese M, Boateng J, et al. Determination of total phenolics, lavonoids and antioxidant and chemopreventive potential of basil (ocimum basilicum L. and ocimum tenuilorum L.). International Journal of Cancer Research. 2009; 5(4): 130-143. doi: $10.3923 /$ ijcr.2009.130.143 